\title{
Symptom patterns in women with premenstrual syndrome complaints: a prospective assessment using a marker for ovulation and screening criteria for adequate ovarian function
}

Herdis Sveinsdottır RN MS

Assistant Professor, Department of Nursing, University of Iceland, Reykjavik, Iceland

and Nancy Reame PhD RNFAAN

Associate Professor of Parent-Child Nursing, University of Michigan, Ann Arbor, Michtgan, USA

SVEINSDOTTIR H \& REAME N (1991) Journal of Advanced Nursing 16, $689-700$

Symptom patterns in women with Premenstrual Syndrome complaints: a prospective assessment using a marker for ovulation and screening criteria for adequate ovarian function

This study examined the symtom patterns of women seeking help for

Premenstrual Syndrome (PMS) complaints Seven women who were less than 35 yrs, withun $10 \%$ of ideal body weight and who had expenenced a full-term pregnancy, completed a daily health diary during an ovulatory menstrual cycle In the luteal phase, symptom summary scores of the PMS group increased $(P<005)$ and were markedly higher $(P<05)$ from baselıne acyclic scores of four ovulatory women who denied menstrual-related distress To examine severity changes in individual symptoms, a total of 399 cases representing 57 symptoms from the seven 45-day diaries were evaluated for menstrual cycle entrainment Of the 246 symptoms that met the criteria for a cycle phase change $(62 \%)$, the dassic PMS pattern of low/high seventy was the most common (40\%) Seven different subtypes of the PMS pattern were identified, four of these subtypes demonstrated a severity score elevation at ovulation as well as dunng the premenstruum For individual women, the majority of symptoms (65\%) displayed only two pattern types, suggesting a common rhythmic entrainment of symptom intensity

\section{INTRODUCTION}

Women in today's society are in limbo as to what action to take with respect to their menstrual discomforts Feminists (Laws 1983, Rome 1986) have criticized the medicalization

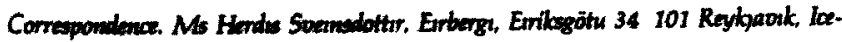
land of Premenstrual Syndrome (PMS) at the same time that experts within the medical profession advocate medical treatment (Dalton 1987) Physically able women are accustomed to carng for their menstrual needs, seeking professional assistance only when they perceive that something about their cycle is different Often it is a nurse who 
venfes the nature of their situation and assists them to plan further action A self-care approach is a logical strategy for managing menstrual health problems To serve as a selfcare advocate for women with premenstrual discomforts, the nurse must be knowledgeable about the influence of the menstrual cycle on health and well-being

Clinicians since the time of Hippocrates have recognized that there are physical and psychological changes that occur in women prior to their menses In the nineteenth century, physicians expressed concern regarding the possible deletenous 'effects of woman's 'penodical ordeal' on her general functioning In the extensive medical literature of the time concerning the relationship between femininity and health, the impact of the menstrual cycle is repeatedly considered, however, no attempts were made to define particular effects of different phases

Outside the medical literature there are references to premenstrual disturbances affectung health and behaviour The socially deviant behaviour of August Strindberg's heroine, Miss Julie, is explained by one of her servants 'It's just her time coming on She's always queer then ' Since Strundberg, a number of writers and dramatısts - including Anas Nin, Dons Lessing, Willam Faulkner, John Fowles and Fay Weldon - have made similar references to menstrually related alterations in mood and behaviour (Clare 1983)

It was not until 1931 that these alterations were first described in the health care hiterature Frank (1931), a gynaecologist, attributed the premenstrual changes to faulty ovarian function, whereas Horney (1931), a psychatrist, explained them as the manifestation of repressed sexual desire and power Among contemporary researchers there is still disagreement on the aetiology of PMS Numerous theones have been proposed, ranging from the purely psychological to the biochemical, but consistent data in support of any single aetiology are lacking

The most striking features of studies during the last decade relate to their variable and disparate findings Over 150 symptoms have been identified when data are collected by use of retrospective questionnares Only recently has prospective information been obtained about the symptom pattens in women with PMS (Magos et al 1986), in keeping with the recommendations of a US government panel to define proper diagnostic critena (Blume 1983)

Estumates of the prevalence of PMS vary greatly from sample to sample (Shader \& Ohly 1970, Hargrove \& Abraham 1982), ranging as high as $90 \%$ (Sutherland \& Stewart 1965) Recent studies, however, report that even though $30 \%$ to $50 \%$ of women expenence muld or moderate symptoms perimenstrually, only $10 \%$ to $20 \%$ expen- ence severe and disabling symptoms, with $5 \%$ to $7 \%$ of women exhibiting the classical PMS pattern (Woods 1986, Johnson et al 1988, Andersch et al 1986). Woods (1986), when studying perimenstrual symptoms using prospective data collection methods, concluded that 'women who report moderately and extremely severe symptoms clearly constitute a minonty of women'

\section{Variability in symptom incidence}

The striking variability in symptom incidence has led one of the leading researchers in this field to advise that

cyclic physical and emotional changes occur with such frequencies in relation to the menstrual cycle that they must be considered a normal event in the lives of most women of reproductive age, and that for the majonty of women, physical and emotional changes associated with the menstrual cycle are munor and well tolerated

(Reid 1986)

PMS researchers and clinicians are acknowledging that a part of the 'variability' of PMS can be attributed to its conceptualization and to inadequate research methodologies Femmists (Laws 1983, Rome 1986) have cnticized traditional conceptualizations of PMS, suggesting that the labelling of PMS as an illness is a way to ignore and invalıdate female rebelliousness They emphasize the importance of women being accountable for their actions Zita (1988), when criticizing the medicalization of premenstrual changes, pointed out that

the step from observable cyclicity to the presumption of pathology, which requires disease model thinking, is an epistemic leap that requires careful scrutiny of the evidence

Cnitics have also pointed to investigator bias in the design of symptom measurement tools (Woods 1986, Zita 1988) Most of the symptom checklists used in PMS studies emphasize negative symptoms and fail to include positive changes in health, mood or behaviours Rome (1986) refers to Emly Cullpepper, who has run menstrual workshops for years and reported that women will send her drawings, poems and other creative work that they have felt particularly inspired to do premenstrually Miota (1987), who has been treating women with PMS since 1981, has also reported that artists mention the premenstruum as a creative penod

A number of review articles in the 1980s have defined important methodological weaknesses of early studies (Reid 1986, Rubinow \& Roy-Byme 1984, Abplanalp 1983). 
A major methodological problem of the past has been the use of retrospective questionnaires for data collection which has been shown to favour the recall of perimenstrual symptoms but not those at other times of the month (Zita 1988, Miota 1987) Guidelınes have now been developed for the dragnosis of PMS relying heavily on the prospective assessment of multiple cycles to confirm retrospective self-reports (Blume 1983)

Given the general acceptance among researchers of an association between endocrine factors and premenstrual changes, it is somewhat surprising that few studies of symptom distribution and classification have adequately defined the hormonal status of the study populations Endocrinologically diverse samples have included infertility clinic patients, women after gynaecology surgery, college populations, pregnant women and oral contraceptive users (Rubinow \& Roy-Byme 1984) Even in studies of nonpregnant, menstruating subjects, screening critena have falled to account for the influence of ageing, body weight and fertility status as important predictors of adequate ovanan function Oestrogen production is dramatically influenced when body weight falls below or exceeds $20 \%$ of ideal body weight (Warren \& Vande Wiele 1973, Warren et al 1974, Frisch 1985) and may begin to diminish as early as age 35 as a result of the normal premenopausal changes in the reproductive axis (Speroff et al 1989) In women with a history of multiple pregnancy losses, a luteal phase defect in ovanian progesterone secretion has been recognized as an aetiological factor (Sitten \& McDonald 1973) Menstrual cycle disruptions or irregularities typically occur as later sequelae of these hormonal aberrations and not as an early sign of dysfunction

\section{Ovulation}

Much attention has been paid in the literature to the need for the confirmation of ovulatory status of participating subjects through concurrent hormonal measures (Backström \& Hammerback 1986, Halbreich et al 1988, Schechter et al 1989) Studies of menstrual symptoms have frequently relied on cycle length and regularity as evidence of ovulation, using days before or after menses onset as reference points for estımating the follicular and luteal phases of the ovaran cycle (Casper \& Powell 1986, Rosen et al 1988, Morse \& Dennerstein 1988, York et al 1989) Basal body temperature changes across the cycle have a less than acceptable false-positive rate $(20 \%)$ as a clinical marker of ovulation (Speroff et al 1989). Thus, in many cases, conclusions have been drawn about a relationship between reproductive biology and symptom changes based on data from heterogenous samples lackıng hormonally defined cycle phases

Few studies look beyond a summary symptom score which fals to give a picture of the nature of the types of symptoms and how they change in the cycle In most studies the symptoms have been clustered together in order to find simulanities (Dalton 1987, Halbreich et al 1982) The patterns of symptom clusters have also been recorded (Magos et al 1986) but the pattern of individual symptoms, and whether individual symptoms pertaining to the same cluster display the same pattern over the menstrual cycle, has not been assessed

It would appear that there is a need for further refinement of PMS research methodologies, particularly with respect to sample selection and design considerations In keeping with the recommendations of a number of critics to improve sample homogeneity, collect prospective data and better define the hormonal milieu, the following study was conducted

\section{METHODOLOGY}

The purpose of this prospective exploratory study was to examine the symptom charactenstics and patterns of heal thy women with adequate ovarian function who identify themselves with PMS For the purpose of the study PMS was defined as

the cyclic occurrence of symptoms that are of sufficient severity to interfere with some aspects of life and appear with a consistent and predictable relationship to menses

(Rubinow \& Roy-Byrne 1984)

This definition takes into account the following aspects the type of symptoms expenenced, the intensity of the symptoms, the relationshup between symptom appearance and menstruation, and the symptomatic baseline on which symptoms fluctuate

\section{Sample selection criteria}

Subjects were recruited from applicants to a larger study (NIH-NU-01373) who were drawn from patient populations seekng medical treatment for PMS complaints Eligibility for participation was based on the following criteria designed to ensure a biologically similar population and meet the screening recommendations suggested by others (Rubinow \& Roy-Byrne 1984, Abplanalp 1983)

1 negative history for chronic or current medical, gynaecological and endocrine illness 


2 $\pm 10 \%$ of ideal body weight
3 21-35 years of age
4 regular menses every 25 to 32 days
5 at least 6 months postpartum, nonbreastfeeding
6 negative history for oral contraceptives or other
chronic medications for at least 6 months
7 negative history for psychiatnc disorder
8 history of at least one full-term pregnancy
9 history of premenstrual complaints for at least 6
months and self-perception of having severe PMS
10 willing to delay medical or behavioural treatment for
one cycle

\section{Study protocol and measures}

The study was approved by the Institutional Review Board of the University of Michigan School of Nursing and was performed after written informed consent had been obtained The women completed a daily health diary during one ovulatory cycle An ovulatory cycle was defined as one in which the presence of a midcycle urinary luteinizing hormone surge was detected using the First Response Ovulation Predictor Test (Tambrands Inc) durnng a menstrual cycle which was preceded by two cycles of sumular regulanty This enzyme-linked, immunosorbent assay for use in the home measures lutemizing hormone (LH), which normally increases in female urne at midcycle as a stimulus for ovulation (the LH surge) Subjects began testing firstmorning unnes approximately 16 days before the next expected menses and continued for 6 to 9 days until the detection of the LH surge, measured by a significant colour change in the test medium

\section{Symptom assessment}

Menstrual symptoms were self-assessed by use of the Woods Daily Health Diary (DHD) This instrument includes a symptom checklist based on item pools generated from three well-studied menstrual questionnaires (Moos 1968, Steiner et al 1980, Halbreich et al 1982) General symptoms frequently expenenced by women of this age group are also included in the checklist so that the domain of symptoms is not restricted to menstrual symptoms Women are also given the option of adding other symptoms not listed. Participants are asked to indicate which symptoms they expenience each day and to rate the seventy of their symptoms on a five-point scale where $0=$ no expenence, $1=$ barely noticeable, $2=$ mild, $3=$ moderate and $4=$ severe It takes approximately 10 minutes to complete the DHD
In order to identify a summary symptom pattern for each subject across the menstrual cycle, the method developed by Woods (1986) was used Data from the daily dianes were synchronized with menstrual cycle days, converting calendar days into cycle days (day $1=$ first day of menses) Summary symptom scores for the $\mathbf{4 0}$ menstrual symptoms were determined from data collected between days 4 through to 10 in the follicular phase and days -7 through to -1 before menses in the luteal phase The mean of the three most severe days was calculated for both the follicular and the luteal phase and a mean difference score was determined

\section{Definition of symptom scores in ovulatory women without menstrual-cycle-related complaints}

In a random community sample of 345 menstruating women of diverse age and body weight, the Woods method detected a significant premenses rise in symptomatology in only $8 \%$ of the subjects, postmenstrual scores were 10 or less and premenstrual scores were greater than 18 with a difference score of 11 or more (Woods 1986) As one-third of this random sample were oral contraceptive users and no hormonal measures were used to assess reproductive function, the incidence and charactenstic scores associated with the follicular and luteal phases of ovulatory cycles in the absence or presence of premenstrual syndrome could not be determined

In order to estimate the expected baseline level of symptomatology in ovulatory women, four normal volunteers who reported no significant symptoms entrained to their menstrual cycles and who fulfilled criteria 1 to 7 agreed to complete the DHD for 1 month All four women demonstrated ovulatory levels of plasma oestrogen and progesterone in the week pror to menses in the two menstrual cycles preceding their participation For this group, the mean summary symptom score was $191 \pm 1$ in the follicular phase and $196 \pm 1$ in the luteal phase (Table 1) For all four individuals, the mean difference score failed to meet criteria for a signuficant change between the two phases, although the level of symptomatology among the women was diverse

\section{Summary pattern of severity change}

A summary pattern of the seventy change in the 40 menstrual symptoms across the cycle phases were determined by the method developed by Mitchell et al (1984) For each subject, a pattern was defined in relation to the follicular phase (FP) and luteal phase (LP) of the menstrual cycle according to low $(\mathrm{L})$ or high $(\mathrm{H})$ seventy as described below In order to say that an adequate cycle-phase 
Table 1 Symptom seventy pattern, "length of cycle and day of $\mathrm{LH}$ surge for subjects

"The method used to identify symptom severity pattern was developed by Mitchell et al (1985)

\begin{tabular}{|c|c|c|c|c|}
\hline $\begin{array}{l}\text { Mean } \\
\text { follicular } \\
\text { score }\end{array}$ & $\begin{array}{l}\text { Mean } \\
\text { luteal } \\
\text { score }\end{array}$ & $\begin{array}{l}\text { Difference } \\
\text { of the } \\
\text { means }\end{array}$ & Pattern & $\begin{array}{l}\text { Length } \\
\text { of cycle } \\
\text { (days) }\end{array}$ \\
\hline
\end{tabular}

PMS subjects $(n=7)$

\begin{tabular}{cclllll}
001 & 423 & 695 & 272 & $\mathrm{H} / \mathrm{Her}$ & 30 & 18 \\
002 & 87 & 223 & 137 & $\mathrm{~L} / \mathrm{H}$ & 31 & 17 \\
003 & 587 & 353 & 233 & $\mathrm{Her} / \mathrm{H}$ & 25 & 13 \\
004 & 90 & 210 & 170 & $\mathrm{~L} / \mathrm{H}$ & 26 & 13 \\
005 & 60 & 317 & 257 & $\mathrm{~L} / \mathrm{H}$ & 30 & 14 \\
006 & 277 & 837 & 560 & $\mathrm{H} / \mathrm{H}$ er & 30 & 17 \\
007 & 63 & 993 & 930 & $\mathrm{~L} / \mathrm{H}$ & 30 & 16 \\
Mean & $227 \pm 21$ & $518 \pm 32$ & $366 \pm 28$ & & $289 \pm 23$ & $154 \pm 21$ \\
\multicolumn{1}{l}{ Control subjects $(n=4)$} & & & & & \\
101 & 268 & 173 & 95 & & & \\
102 & 322 & 340 & 18 & & & \\
103 & 137 & 210 & 73 & & & \\
104 & 37 & 60 & 24 & & & \\
Mean & $191 \pm 13$ & $196 \pm 12$ & $53 \pm 37$ & & &
\end{tabular}

difference existed, the subject had to demonstrate a difference in symptom severity between the follicular and luteal phase of equal or more than 11

1 Summary patterns of increasing seventy across the cycle $L / H$ low SS at the FP, high SS at the LP (the typical PMS pattern) - the follicular score $<10$ and the luteal score is $\geq 18, \mathrm{H} / \mathrm{Her}$ high SS at the FP, higher SS at the LP - the follicular score $>10$ and the luteal score is $\geq 18$

2 Summary patterns of decreasing seventy across the cycle Her/H higher SS at the FP, high SS at the LP the follicular score $\geq 18$ and the luteal score is $>10$, $H / L$ high SS at the FP, low SS at the LP - the follicular score $\geq 18$ and the luteal score is $<10$

3 Summary patterns showing no seventy change across the cycle $L / L$ low SS at the FP and LP - the cycle phase difference is $<5$, the follicular score is $<10$ and the luteal score is $<18$ or the follicular score is $<18$ and the luteal score is $<10, H / H$ high SS at the FP and LP - the cycle phase difference is $<5$, the follicular score is $\geq 10$ and the luteal score is $\geq 18$ or the follicular score is $\geq 18$ and the luteal score is $\geq 10$

This method was then adapted in order to identify seventy patterns for each of the DHD symptoms including those not considered menstrual-related For each symptom, a pattern was defined in relation to the follicular phase (FP) and luteal phase (LP) of the menstrual cycle according to low $(L)$, medium $(M)$ or high $(H)$ seventy

\section{RESULTS}

The mean age of the PMS subjects was $318 \pm 2$ years Durng study, the mean length of the menstrual cycle was $289 \pm 2$ days with the day of the $\mathrm{LH}$ surge occurring between cycle day 13 and 18 (mean $=154 \pm 2$ )

Table 1 presents the mean summary symptom scores and patterns of the PMS subjects compared with those of the normal volunteers Although the mean summary symptom score for the follicular phase was simular for both groups, the mean score of the luteal phase of the PMS group was higher than for the control group $(P=<005$, Mann Whitney $U, U=35$ ) The mean of the difference between the means also reached significance $(U=05)$

With the exception of subject 3, the PMS group displayed summary pattern types of increasing severity across the menstrual cycle Figure 1 shows summary patterns of all subjects demonstrating the low/high, high/ higher and higher/high patterns that were observed when the 40 menstrual symptoms were analysed together Figure 2 compares a graph of the mean total symptom seventy score for the study group and the control group over one menstrual cycle for the 40 symptoms used for calculations of the symptom seventy score

\section{Severity changes}

To examine seventy changes in individual symptoms, a total of 399 cases representing all 57 symptoms from the 

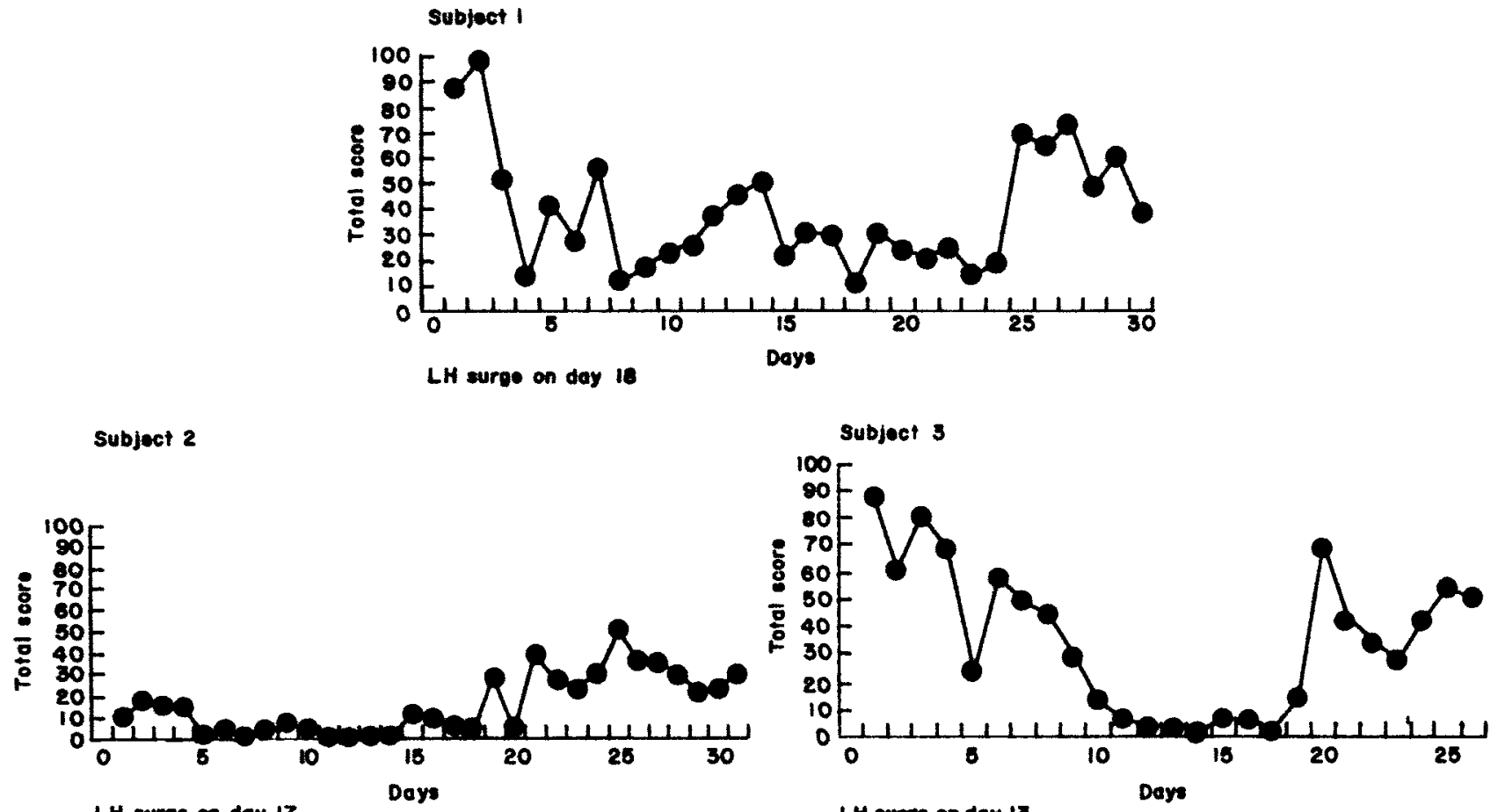

LH ourge on day 17

LH aurge on day 13
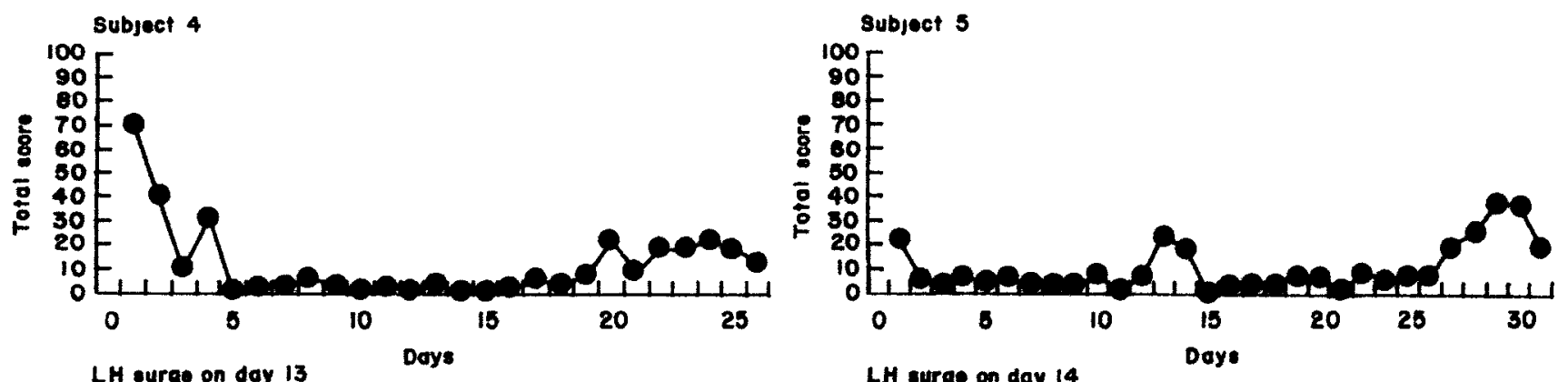

Subject 6
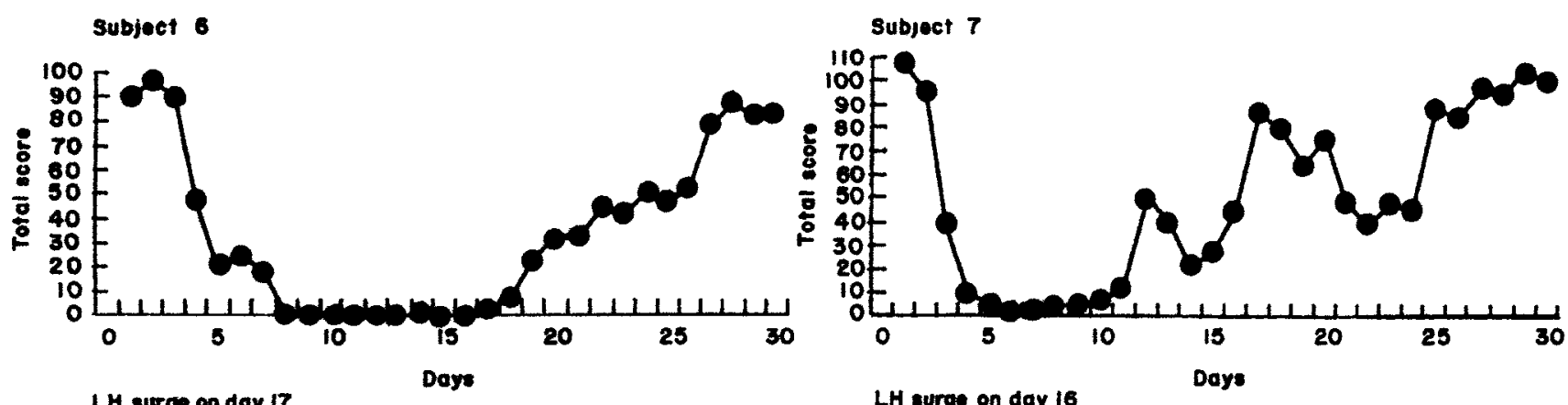

LH surge on day 17

LH surge on day 16

Figure $1 \mathrm{Graph}$ of symptom pattern for $\mathbf{4 0}$ symptoms all subjects

seven 45-day dianes were evaluated for menstrual-cycle entrainment (Table 2) Of the 246 cases $(62 \%)$ that met the criterna for a cycle-phase change, $197(80 \%)$ exhibited an increase in the seventy score from the follicular to the luteal phase while $49(20 \%)$ showed a decreasing symptom score For those cases that increased in seventy, $98(40 \%)$ met the critena for the low/high pattern type commonly associated with premenstrual syndrome In addition, $22(45 \%)$ of the 49 cases where symptom seventy decreased in the luteal phase were for positive symptoms

With the exception of 'intentional self-injury', all other symptoms were shown to demonstrate at least one of the increasing or decreasing severity patterns entrained to the cycle in one or more dianes Thirty of the $\mathbf{5 7}$ symptoms 


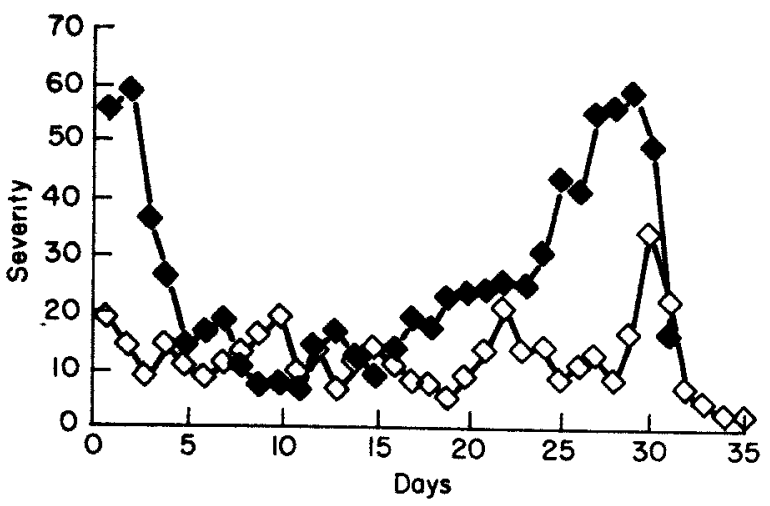

Figure 2 Symptom seventy scores for 40 symptoms over one menstrual cycle PMS group vs control group $\downarrow=$ PMS group $(n=7), \diamond=$ control group $(n=4)$

exhibited a pattern of increasing severity exclusively, while six symptoms (backache, bursts of energy, feelings of wellbeing, in control, increased activity, increased sexual desire) demonstrated patterns predominantly of decreasing seventy over the cycle

The symptom patterns with the highest incidence expenenced by the group were the low/high and high/higher patterns (Table 2) Although no symptom demonstrated a seventy pattern that was common to all subjects, sIx of the seven diaries $(86 \%)$ displayed a low/high pattern for 'sensation of weight gain', five (71\%) showed a high/higher pattern for anxiety, fatigue and impatience, as well as a higher/high pattern for in control In four dianes (57\%), a low/high pattern was demonstrated for the following craving for specific foods, increased appetite, increased food intake, tender breasts, rapid mood changes, restlessness and swelling of hands or feet Despite the overall pattern of decreasing seventy in the luteal phase observed for subject 3, a low/high pattern was demonstrated for the symptoms 'forgetfulness' and 'rapid mood changes'

As the low/high symptom pattern was most commonly observed in this sample and is considered a hallmark of the premenstrual syndrome, seventy scores of those symptoms ( $n=98$ ) meetung the low/high criteria were plotted according to cycle phase to assess vanability Seven different subtypes of the low/high seventy pattern were observed over the cycle (Figure 3) In type A, the symptom occurs only in the premenstruum, in $B$, the symptom is seen durng menstruation and in the premenstruum, types $C$ and $D$ are seen in relation to menstruation, ovulation and in the premenstruum; types $\mathrm{E}$ and $\mathrm{F}$ are seen in relation to ovulation and in the premenstruum, but not during menstruation. Symptoms showing random fluctuations across the luteal phase were assigned to the irregular type $G$ For all subjects, at least $65 \%$ of the symptoms displayed only two of the seven low/high vanations

\section{DISCUSSION}

Six of the seven subjects who reported suffening from chronic premenstrual syndrome exhibited significant premenstrually related symptomatology by demonstrating an adequate difference in summary scores between the follicular and luteal phase The selection cntena used to rule out confounding psychological conditions and ensure adequate ovarian function would seem to be useful to confirm selfperceptions, as approximately $50 \%$ of women who seek medical treatment for PMS complaints will fall to demonstrate menstrual-related changes when prospective measures are used (Rubinow et al 1985, Endicott \& Halbreich 1982) Others have previously reported that when women present with PMS and fulfill diagnostic crnteria, they will demonstrate significant exacerbation of at least some symptoms premenstrually when prospective measures are used (Magos et al 1986)

The large number of symptoms observed to show increasing intensity after ovulation point to the great diversity of symptomatology associated with ovulatory cycles in healthy women with PMS complaints and suggest that factors other than abnormal body weight, perimenopausal changes or subfertility can account for the disparate psychobıologic symptoms

\section{Enormous variability}

Figure 1 also demonstrates the enormous variablity among women with PMS complaints The need to look beyond summary symptom scores, and analyse patterns, is evidenced by the difference in pattern between subject 1 and subject 6 , even though both have the same $\mathrm{H} / \mathrm{Her}$ pattern The same applies for subjects 4 and 5 Subject 4 has menstrual and premenstrual complaints, whereas subject 5 has ovulatory and premenstrual complaints, but both are classified as having $\mathrm{L} / \mathrm{H}$ pattern

The findings in subject 3 of an overall improvement in summary scores during the luteal phase highlight the need for individual symptom monitoring when conducting a prospective clinical assessment This subject had been prospectively diagnosed for premenstrual migraine headache durng the 6 months pror to study Despite an improvement in the overall summary score in the luteal phase due to the occurrence of several positive life events, the premenstrual entrainment of a subset of symptoms (forgetfulness and rapid mood changes) persisted Cycleto-cycle variability in PMS seventy has been previously documented (Johnson 1987)

Of the 98 cases that displayed the $\mathrm{L} / \mathrm{H}$ symptom seventy pattern, 22 of these ( $2245 \%$ ) displayed a pattern where symptom remission occurred with the onset of 
Table 2 Symptom seventy pattern ${ }^{*}$ for individual symptoms for the PMS group $(n=7)$
Change in severity**

\begin{tabular}{ll}
\hline Increasing & Decreasing \\
\hline$/ M^{*} L / H \quad H /$ Her Total & $M / L \quad H / L \quad H e r / H$ Total
\end{tabular}

\begin{tabular}{|c|c|c|c|c|c|c|c|c|}
\hline Abdominal pain, discomfort & & 2 & & 2 & & 1 & & 1 \\
\hline Anger & 1 & & 2 & 3 & & & & \\
\hline Anxiety & & & 5 & 5 & & & & \\
\hline Awakening durning the night & & 2 & & 2 & & & & \\
\hline Backache & 1 & 1 & & 2 & 2 & 1 & & 3 \\
\hline Bloating or swelling of abdomen & & 3 & 3 & 6 & & & & \\
\hline Blurred or fuzzy vision & & 1 & & 1 & & & & \\
\hline Bursts of energy or activity + & & 1 & 1 & 2 & & 1 & 2 & 3 \\
\hline Confusion & & 3 & & 3 & & & 1 & 1 \\
\hline Cramps-utenne or pelvic & & 2 & 1 & 3 & & 1 & & 1 \\
\hline $\begin{array}{l}\text { Craving for specific foods or } \\
\text { tastes }\end{array}$ & & 4 & 1 & 5 & 1 & 1 & & 2 \\
\hline Craving for alcohol & & 1 & & 1 & & & & \\
\hline Decreased appetite & & 2 & & 2 & & 2 & & 2 \\
\hline Decreased food intake & & 1 & 2 & 3 & & 2 & & 2 \\
\hline Decreased sexual desire & 1 & 2 & 2 & 5 & & & & \\
\hline Depression & & 2 & 3 & 5 & & & & \\
\hline Desire to be alone & 1 & 2 & 2 & 5 & & & & \\
\hline Diarrhoea & 1 & 1 & 1 & 3 & & & 1 & 1 \\
\hline Difficulty concentratıng & 1 & 1 & 2 & 4 & & & & \\
\hline Difficulty in getting to sleep & & 2 & 1 & 3 & & & 1 & 1 \\
\hline Difficulty makıng decisions & 1 & 1 & 2 & 4 & & & & \\
\hline Dizziness or lightheadedness & & & 2 & 2 & & & & \\
\hline Early morning awakening & & 1 & 4 & 5 & & & & \\
\hline Fatigue or tiredness & & & 5 & 5 & & & 1 & 1 \\
\hline Feelings of gult & & 2 & 2 & 4 & & 1 & & \\
\hline Feelings of well being + & & & 1 & 1 & & 1 & 3 & 3 \\
\hline Forgetfulness & & 3 & 1 & 4 & & & & \\
\hline General aches and pains & & 1 & 2 & 3 & & & 1 & 1 \\
\hline Headache & 1 & 2 & 1 & 4 & & 1 & 1 & 2 \\
\hline Hostility & 1 & 1 & 2 & 4 & & & & \\
\hline Hot flashes or sweats & & 1 & 1 & 2 & & & & \\
\hline
\end{tabular}

menses (patterns C, E and F) Woods et al (1982) reported that in healthy normal women, premenstrual and menstrual reports of the same symptoms were highly correlated They concluded that it was reasonable to study penmenstrual distress as a single construct In this study, the symptom patterns for $\mathbf{4 0}$ symptoms (Figure 1) validates that. However, our findings regarding the $\mathrm{L} / \mathrm{H}$ symptom severity pattern indicate that, for some women with chronic premenstrual complaints, menstrual and premenstrual distress may be more distinct

Fufty-one (52\%) of the 98 cases showing the $\mathrm{L} / \mathrm{H}$ pattern were also present durng the week of ovulation (patterns
C, D, E and F), while only 17 (17 35\%) were present exclusively in the premenstruum (pattern A) Although it is not known to what extent the monitoring of unne at midcycle may have heightened symptom awareness, these findings support other reports (Koeske \& Koeske 1975, Sheldrake \& Cormack 1976) that women who identify themselves with severe PMS are likely to demonstrate symptomatology that precedes or persists beyond the late luteal week.

In this study, a large number of symptoms demonstrated a H/Her entrainment to the luteal phase, thus contributing to the $\mathrm{H} / \mathrm{Her}$ summary score achieved by three of the seven subjects when overall symptom patterns were 
The method used to identify symptom severity pattern was adapted from Mitchell et al (1985)

"From follicular to huteal $\mathrm{L} / \mathrm{M}=$ low/ medium $\mathrm{L} / \mathrm{H}=\mathrm{low} /$ high (the typical PMS pattern), $\mathrm{H} / \mathrm{Her}=$ hugh/hugher, $\mathrm{H} / \mathrm{L}=$ hugh $/$ low, $\mathrm{M} / \mathrm{L}=$ medium $/$ low Her/H = hugher/high.

+Symptoms indicate positive feelings

Change in severity**

Increasing

Decreasing

L/M $\mathrm{M}^{*} \mathrm{~L} / \mathrm{H} \quad \mathrm{H} / \mathrm{Her}$ Total $\mathrm{M} / \mathrm{L} \quad \mathrm{H} / \mathrm{L} \quad \mathrm{Her} / \mathrm{H}$ Total

\begin{abstract}
Impatient, intolerant
Impulsıveness +

In control +

Increased activity +

Increased appetite

Increased food intake

Increased sensitivity to cold

Increased sexual desire +

Increased sleeping

Intentional self injury

Irritable

Lonely

Lowered co-ordınation or clumsiness

Lowered desire to talk or move

Nausea

Nervousness

Out of control

Panful or tender breasts

Rapid mood changes

Restlessness or jtteriness

Sensation of weight gain

Skın disorders

Surcidal ideas or thoughts

Swelling of hands or feet

Tearfulness, crying easily

Tension
\end{abstract}

Total

$\begin{array}{cccccccc} & 1 & 5 & 6 & & & & \\ 1 & 1 & 1 & 3 & & & & \\ & & 1 & 1 & & & 5 & 5 \\ & & 3 & 3 & 1 & 1 & 2 & 4 \\ & 4 & 1 & 5 & 1 & & & 1 \\ & 4 & 1 & 5 & 1 & & & 1 \\ & 3 & 1 & 4 & 1 & 1 & & 2 \\ & & 1 & 1 & & 3 & 1 & 4 \\ & 2 & & 2 & & 1 & 1 & 2\end{array}$

$\begin{array}{llll}1 & 1 & 3 & 5\end{array}$

$\begin{array}{lll}2 & 1 & 3\end{array}$

2113

$\begin{array}{llllll}1 & 1 & 2 & & 1 & 1 \\ 1 & & 1 & 1 & & 1\end{array}$

44

246

$\begin{array}{lll}4 & 1 & 5\end{array}$

$6 \quad 1 \quad 7$

1326

11

44

112

134

$\begin{array}{llllllll}16 & 98 & 83 & 197 & 7 & 19 & 23 & 49\end{array}$ assessed Some experts have argued that subjects exhibiting a premenstrual exacerbation of symptoms (rather than a premenstrual onset) have other underlying conditions and should not be considered eligible for the PMS diagnosis (Dalton 1987) It is interesting to note that summary scores for three of the four normal volunteers in this study were clearly elevated above the low range in both phases of the cycle, suggesting that there may be a baseline level of everyday stress upon which menstrual-cycle biology is superimposed in women afficted with PMS, thus accountIng for a $\mathrm{H} / \mathrm{Her}$ pattern Further, the data from the normal volunteers also suggest that chronic dally stress across the menstrual cycle is not necessarily a trigger for premenstrual symptomatology. These observations suggest that other predisposing factors may play a role in susceptibility to ovanan hormonal influences
Although multiple $\mathrm{L} / \mathrm{H}$ patterns (Figure 3) were observed among the sample, the patterns demonstrated by individual women were few in number and similar for a majority of their symptoms This finding would support a role for a biorhythmic entrainer in PMS aetıology that is responsible for eliciting a unique set of symptoms in each woman Further analyses of the other patterns that showed increasing seventy scores $(\mathrm{H} / \mathrm{Her}$ and $\mathrm{M} / \mathrm{H})$, as well as further analyses of the patterns over multiple ovulatory cycles, is needed before conclusions can be drawn

The individual symptoms that most often displayed an increasing symptom seventy pattern were sumilar to those that have been reported to be the most bothersome or disabling in the premenstruum(Woods 1986, Halbreich et al 1982, Woods et al 1982, Shaver \& Woods 1985) It should 

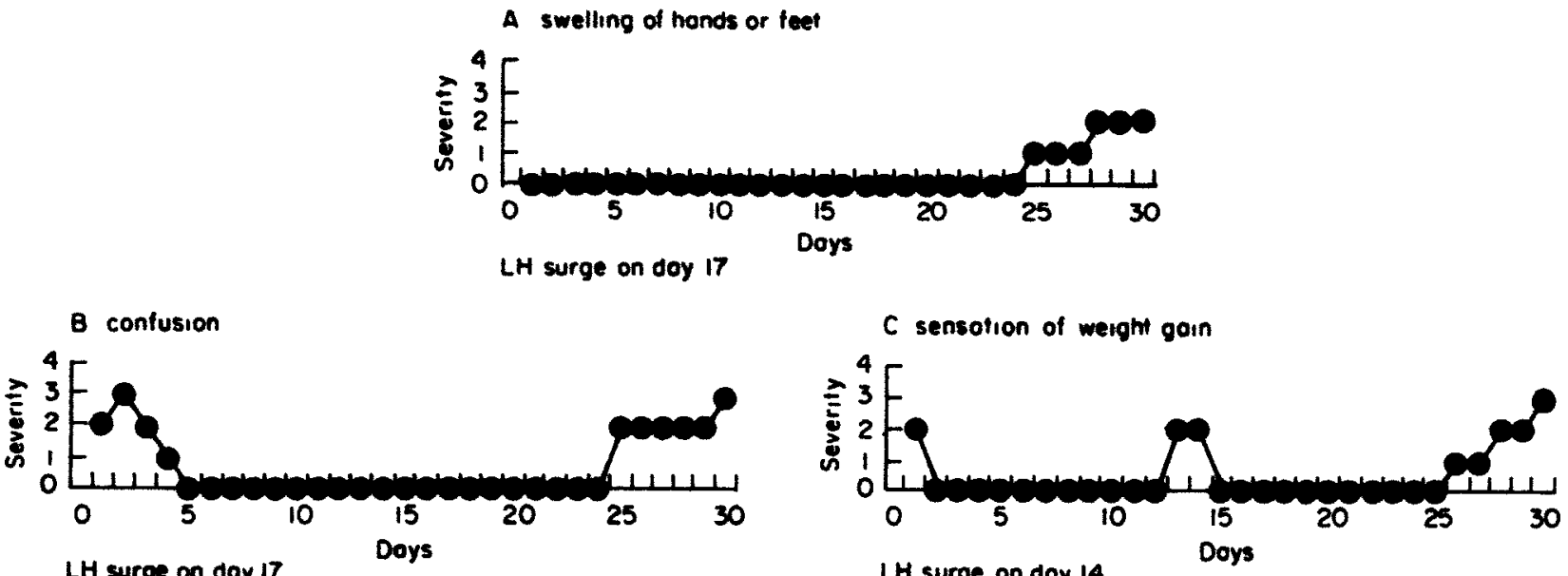

LH surge on doy 17

LH surge on doy 14

D restlessness or jitteriness

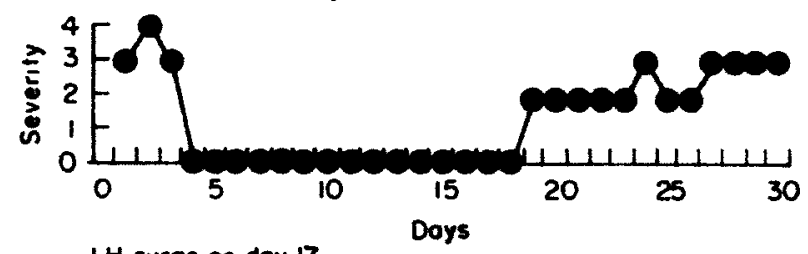

E increosed oppetite

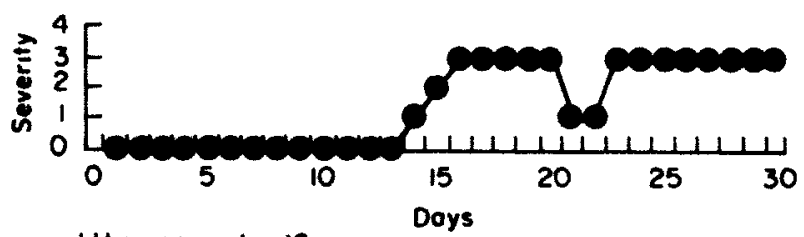

LH surge on doy 16

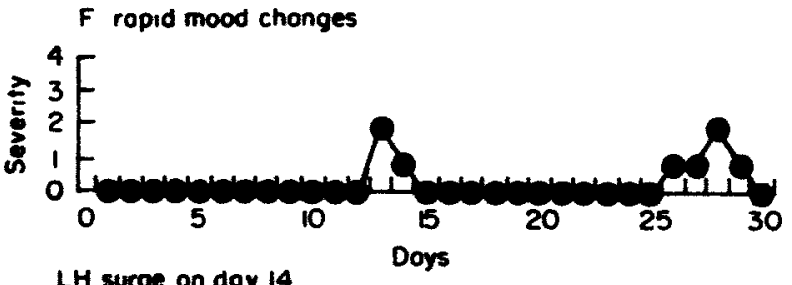

G blurred or fuzzy vision

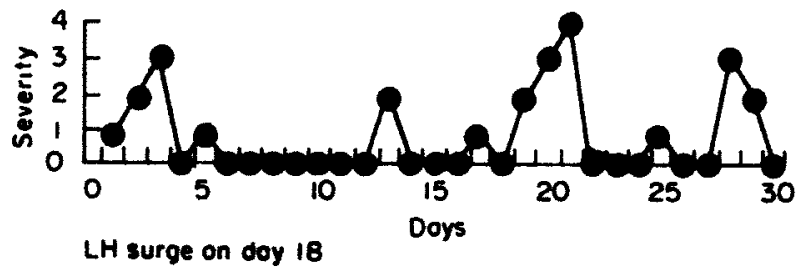

Figure 3 Different types of $\mathrm{L} / \mathrm{H}$ symptom seventy patterns $\mathrm{A}=$ symptom not present until the premenstruum, $\mathrm{B}=\mathrm{h}$ gh symptom seventy score during menses, that dropped down following menses and increased again in the premenstruum, $C=$ high symptom seventy score during menses, that dropped following menses, increased again during the week of ovulation, dropped down again and increased in the premenstruum, $D=$ high symptom seventy score during menses, that dropped down following menses, increased again during the week of ovulation and stayed high, $\mathrm{E}=$ symptom not present until duning the week of ovulation, then the seventy score increased and stayed high, $\mathrm{F}=$ symptom not present until duning the week of ovulation, when the seventy score increased for a few days, then it dropped down and was not present until the premenstruum, $G=$ irregular pattern

be noted, however, that four subjects exhibited at least one positive symptom which demonstrated a luteal phase entrainment For example, three subjects reported increased activity and, in two subjects, bursts of energy were more pronounced before menses. This finding of some positive experiences associated with the premenstruum are consistent with reports by contemporary feminists (Rome 1986, Miota 1987)

\section{Weakness of menstrual symptom studies}

A recognuzed weakness of menstrual symptom studies is the difficulty in blinding subjects to the purpose of the investigation. In this study, subjects knew they were participating in an assessment of premenstrual syndrome characternstics The use of the DHD and the LHkat served to remind them of menstrual-cycle phases and thus menstrual symptom inc1dence and seventy may have been increased in the late luteal phase during the expected time of peak distress It can also be argued that an expenmental, halo effect may have been offset by the therapeutic effect of symptom reporting, i e where symptoms improve due to a sense of enhanced mastery achieved through active participation in monitoring body changes Therapeutic benefits have been attributed solely to the use of darly health dianes in establishing a PMS diagnosis (Reid 1986)

\section{Implications for nursing}

From a nursing-care perspective, these findings may have important implications for the promotion of self-care strategies in women with premenstrual syndrome The positive 
aspects of the premenstruum should be pointed out to women presenting themselves with PMS as a way to enhance their abilities to cope with the negative aspects of the premenstruum

\section{Acknowledgements}

This study was supported by National Institutes for Health, Bethesda (grant no NU-01373) The LH kits were generously supplied by Tambrands Inc, New York

\section{References}

Abplanalp JM (1983) Psychologic components of the premenstrual syndrome Joumal of Reproductive Medicine 28, 517-524

Andersch B , Wendestam C. Hahn L \& Öhman R (1986) Premenstrual complaints I Prevalence of premenstrual symptoms in a Swedish urban population Journal of Psychosomatic Obstetrics and Gynaecology 5, 35-49

Backstrom T and Hammerback S (1986) Endocrinological aspects of the premenstrual syndrome Gonadotropin Down-Regulation in Gynecological Practice (Rolland R, Chadhas DR \& Willemsen $W$ eds), Liss, New York, pp 421-428

Blume $E$ (1983) Methodological differences plague PMS research Journal of the American Medical Association 249, 286

Casper RF \& Powell AM (1986) Premenstrual syndrome documentation by a linear analogue scale compared with two descriptive scales American Joumal of Obstetrics and Gynecology 155, 862-867

Clare AW (1983) Psychiatric and social aspects of premenstrual complaint Psychologic Medicane, monograph (suppl 4) Cambridge University Press, Cambridge

Dalton K (1987) Once a Month The Onginal Premenstrual Syndrome Handbook 3rd edn Hunter House, Claremont

Endicott J \& Halbreich U (1982) Psychobıology of premenstrual change Psychopharmacological Bulletin 18, 109-112

Frank R T (1931) The hormonal cause of premenstrual tension Archives of Neurology and Psychiatry 26, 1053-1057

Frisch R.E (1985) Body fat, menarche, and reproductive ability Seminars in Reproductive Endocrnology 3, 45

Halbreich U , Endicott J, Schacrt S \& Nee J (1982) The diversity of premenstrual changes as reflected in the premenstrual assessment form Acta Psychiatnca Scandinavica 65, 46-63

Halbreich U. Alt IH \& Paul L (1988) Premenstrual changes Imparred hormonal homeostasis Neurological Clinics 6, 173-194

Hargrove J T \& Abraham GE (1982) The incidence of premenstrual tension in a gynecologic dinic Joumal of Reproductive Medicine 27, 721-724

Homey K (1931) Die Premenstruelle verstımmungen In Psychatric and social apsects of premenstrual complaint (Clare A.W)
(1983) Psychologic Medicine, monograph (suppl 4) Cambridge University Press, Cambridge

Johnson S R, McChesney C \& Bean J A (1988) Epidemology of premenstrual symptoms in a nonclinical sample I Prevalence, natural history and help-seeking behavior Journal of Reproductive Medicine 33, 340-346

Johnson S R (1987) The epidemiology and social impact of premenstrual symptoms Clinical Obstetrics and Gynecology 30, 367-376

Koeske R \& Koeske G (1975) An attributional approach to moods and the menstrual cycle Joumal of Personality and Social Psychology 31, 474-478

Laws $S$ (1983) The sexual politics of pre-menstrual tension Womens Studies International Forum 6, 19-31

Magos A L , Brincat M \& Studd J W W (1986) Trend analysis of the symptoms of 150 women with a history of the premenstrual syndrome American Joumal of Obstetrics and Gynecology 155, 277-282

Miota P (1987) Presentation at 'Sexuality and the Menstrual Cycle Clinical and Sociocultural Implications' The Conference of the Society of Menstrual Cycle Research, Ann Arbor, Michigan, 4-6 June

Mitchell ES, Lentz M, Taylor D, Allen-Barash N \& Woods NF (1985) Methodologic issues in the definition of the premenstrual symptom Paper presented at the Society of Menstrual Cycle Research, Galvestone, Texas, 10-12 May

Moos RH (1968) The development of a menstrual distress questionnaire Psychosomatic Medicine 30, 853-867

Morse CA \& Dennerstein L (1988) The factor structure of symptom reports in premenstrual syndrome Joumal of Psychosomatic Research 32, 93-98

Reid R L (1986) Premenstrual syndrome a time for introspection American Joumal of Obstetrics and Gynecology 155, 921-926

Rome E (1986) Premenstrual syndrome (PMS) examined through a feminist lens Health Care for Women Intemational 7 , 145-151

Rosen LN, Moghadam L Z \& Endicott J (1988) Psychosocial correlates of premenstrual dysphonc subtypes Acta Psychiatnca Scandinavica 77, 446-453

Rubınow D R \& Roy-Byrne P (1984) Premenstrual syndromes overview from a methodologic perspective Amencan Joumal of Psychiatry 141, 163-172

Rubinow D R, Roy-Byme P, Grover G N \& Post R M (1985) Menstrually-related mood disorders In PMS Current Findings and Future Directions (Oskofsky H J \& Blumenthal SI eds), Amencan Psychiatric Press, Washington DC

Schechter D , Bachmann G A , Vaitukaitis J \& Phillips D (1989) Perimenstrual symptoms time course of symptom intensity in relation to endocrinologically defined segments of the menstrual cyde Psychosomatic Medicane 51, 173-194

Shader RI \& Ohly II (1970) Premenstrual tension, femunity and sexual drive Medical Aspects of Human Sexuality 4, 42-49

Shaver JF \& Woods NF (1985) Concordance of penmenstrual symptoms across two cycles Research in Nursing and Health 8 , 313-319 
Sheldrake P \& Cormack M (1976) Variations in menstrual cycle symptom reporting Joumal of Psychosomatic Research 20, 169-177

Sitten PK \& MacDonald PC (1973) Role of extraglandular estrogen in human endocrinology In Handbook of Physiology Section 7 Endocrinology (Geyer S R, Astwood E B \& Greep RO eds), Amencan Physiology Society. Washington DC

Speroff L., Glass R H \& Kase NG (1989) Clintcal Gynecologic Endocrnology and Infertility 4th edn Willams \& Wilkuns, Baltumore

Steiner M, Haskett RF \& Carroll BJ (1980) Premenstrual tension syndrome the development of research diagnostic cntena and new rating scales Acta Psychiatnca Sacndinavica 62, 177-190

Sutherland H \& Stewart I (1965) A cntical analysis of the premenstrual syndrome Lancet 1, 1180-1183

Warren MP \& Vande Wiele R L. (1973) Clincial and metabolic features of anorexia nervosa Amencan Joumal of Obstetncs and Gynecology 142, 117-435
Warren MP, Jewelewicz R., Dyrenfurth I, Ans R, Khalaf $S$ \& Vande Wiele R.L (1974) The significance of weight loss in the evaluation of pitutary response to LH-RH in women with secondary amenorthea Joumal of Clinical Endocrinological Metabolism 40, 601

Woods NF (1986) Women's health the menstrual cycle Premenstrual symptoms another look Public Health Reports Supplement, 106-112

Woods NF, Most A \& Dery GK (1982) Toward a construct of perimenstrual distress Research in Nursing and Health 5, 123-136

York R, Freeman E, Lowery B \& Strauss J F (1989) Characteristics of premenstrual syndrome Obstetrics and Gynecology 73, 601-605

Zita JN (1988) The Premenstrual Syndrome 'dis-easing' the female cycle Hypatia 3, 77-99 
This document is a scanned copy of a printed document. No warranty is given about the accuracy of the copy. Users should refer to the original published version of the material. 